\title{
SEXUAL PRECOCITY IN THE MALE*
}

\author{
AUGUST STRAUCH, M.D. \\ Attending Physician at the Cook County Hospital, Children's Department; \\ Instructor in Pediatrics, Rush Medical College \\ CHICAGO
}

SYMPTOMS

In sexual precocity of the male we observe as the most striking feature a premature, disproportionate and excessive development of the genitals to the size of those of the full grown man, and also an early development of the secondary sexual characteristics, such as the growth of hairs ad genitalia, ad anum, in the axillae, on the face, and, to a lesser degree, on the remainder of the body, particularly on the extremities; the voice deepens, and in the majority of the cases an increased development of the whole body in length and width with a voluminous musculature (herculean type) and certain psychic features have been noted. This excessive growth, however, is only temporary and the final size of body is not abnormally large, but generally subnormal, since the ossification of the epiphyseal cartilages often occurs prematurely. Thus we observe somatically the ordinary signs of puberty, but at an abnormally early age. In a number of cases this or that symptom was wanting; occasionally there existed obesity.

Whilst in the female at the normal, as well as at the premature age, the time of the gradual onset of the new secretory functions of the sexual glands, that is, the expulsion of a mature ovulum can be determined more or less accurately, due to the accompanying process of menstruation, in the boy the time of the beginning of the secretory function of the sexual glands as manifested in nocturnal pollutions, ejaculations and spermatogenesis, remains as a rule unnoticed. However, the growth of the testes and the penis as a local sign of sexual ripening and the rapid development of the secondary sexual characteristics serve as a more or less reliable symptom of the approaching germinative secretion, the functional capacity.

According to Neurath' $\mathrm{s}^{1}$ publication, only in a few cases of precocity in boys described in the medical literature are to be found exact data as to the onset of emissions and ejaculations of semen.

White, ${ }^{2}$ for instance, describes a case of a boy who, at the age of 2 years, practiced masturbation with resulting ejaculation of sperma.

* Submitted for publication Nov. 24, 1917.

1. Neurath, R.: Ergebn. d. inn. Med. u. Kinderh., 1909, 4, 46.

2. White: Med. Chir. Trans., 1815, 1. 
The 13-year-old boy, yet without crines pubis, reported by d'Outrepont, impregnated a girl 9 years old, who still was without the slightest sign of puberty. This latter case demonstrates the well recognized possibility in the female of a very early ripening of impregnable ovula long before the onset of menstruation. Pellizzi ${ }^{4}$ in his cases likewise demonstrated the presence of spermatogenesis.

Definite data are also often deficient in the literature about the age in the boy at which the first symptoms of precocity appeared. According to the compilation by Netrath ${ }^{1}$ in his monograph, the premature puberty in the male, as far as the respective ages were reported, was completed as follows:

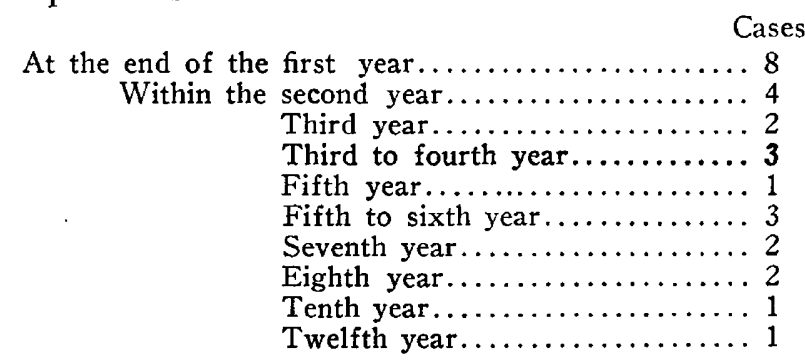

In the majority of the more pronounced cases the excessive and rapid growth of the body had begun during intra-uterine life; whilst the premature and rapid development of the genitalia generally took place only some time after birth. On the other hand, sexual prematurity may commence during intra-uterine life, as boys and girls were born with unusually developed sexual parts that afterward continued developing.

In striking contrast to the premature development and excessive growth of the body in precocity is the persistence of the psychic functions in their infantile stage in most cases. Whilst under normal conditions at the period of physical puberty there sets in also a psychic one, a deep psychic alteration and transformation, a period of "storm and stress," often a tendency toward dreaming and reverie, this is not so in cases of prematurity. The children affected may be physically many years in advance of their age; the mind, however, corresponds, as a rule, to the real age; their behavior is childish, but the premature awakening of the vita sexualis lends it a peculiar color. Rarely does the psychic progress take place pari passu.

In other instances there exists a delayed mental development, a debility, imbecility or even idiocy, as in the cases of Moreau, ${ }^{5}$ Hofacker, ${ }^{5}$

3. d'Outrepont: Quoted from Neurath (Footnote 1).

4. Pellizi: Quoted from Falta (Footnote 31).

5. Moreau: Jour. de méd. de chir. et pharmacol,, 1806, 12, 274.

6. Hofacker: Naturforsch. Versammlung., Düsseldorf, 1903. 
Hudoverning, ${ }^{7}$ Woods, ${ }^{8}$ Ziehn, ${ }^{9}$ Morse ${ }^{10}$ and the 2 -year-old boy mentioned by Heller. ${ }^{11}$ Of course, in case of pre-existing weakmindedness, neither in normal nor in premature puberty could any better development of the psychic functions be expected from these biologic processes.

In imbecille and idiotic children the genitalia more often are retarded (Heller) in their development, kryptorchism being here a very common manifestation of degeneracy. In precocious boys often there exist strong sexual impulses, and occasionally masturbation is mentioned. These facts call especial attention to the pelagogic side of the subject.

Excessive sexual impulses in early childhood may, in tainted neuropathics, exist previous to the anatomic development of the generative organs, and independent of physiologic processes; such sexual sensations, premonitions and impulses may then lead to severe masturbation and aggressivity. The occurrence of these isolated, excessive sexual impulses as a result of cerebral (central) processes without adequate peripheral causes represents a type of partial, namely, psychic precocity, included in the term "sexual paradoxia" (v. Krafft-Ebing) since they occur at an age when they should be absent. V. KrafftEbing, Fere, ${ }^{12}$ Fuchs, ${ }^{13}$ Lombroso, ${ }^{14}$ Moll, ${ }^{15}$ Zambaco $^{16}$ and others reported such cases. It is noteworthy that paradoxic sexual impulses have been observed also in animals. Weston ${ }^{17}$ reported a six weeks' old colt that used to spring on its own mother when 3 months old; on account of its sexual aggressivity it became so dangerous to other colts and calves that its castration was necessary. The author also mentions masturbation in a colt only 2 months old.

\section{ANATOMY AND ETIOLOGY}

Up to the compilation from the literature of Neurath ${ }^{1}$ there were seventeen cases of postmortem and four findings during operations in both sexes; fourteen girls and seven boys. Five of these patients presented neoplasms of the sexual organs, ten or eleven demonstrated

7. Hudoverning-Popovits: Gigantisme précoce avec development précoce, Nouv. iconog. de la Salpêtrière, 1903, 16, 181.

8. Woods, T.: An Extraordinary Case of Early Puberty, Lancet, London, $1882,2,377$.

9. Ziehen: Ber1. klin. Wchnschr., 1906, p. 1095.

10. Morse: Arch. Pediat., 1913, p. 179.

11. Heller, Th.: Grundriss d. Heilpaedagogik., Leipzig, 1912, p. 172.

12. Féré : Précocité et impuissance sexuelle, Ann. d. mal. d. org. génito-urin., 1906, No. 2, p. 1.

13. Fuchs, Alfred: Jahrb. f. Psychiat. u. Neurol., 1903, p. 207.

14. Lombroso: Arch. di Psichiat. [etc.], Torino, 4, 22.

15. Moll, Albert: Das Sexualleben des Kindes, Berlin, 1907, p. 107.

16. Zambaco: L'Encephale, 1882, Nos. 1, 2.

17. Weston: Quoted from Moll (Footnote 15), p. 110. 
neoplasms of the adrenals, three had tumors of the pineal gland; in one case (Wetzler) there existed hydrocephalus congenitus.

Very interesting is the case in which operation was performed by Sacchi ${ }^{18}$ for malign tumor of the testis. At the age of 5 years the boy's left testicle increased to the size of that in the adult, the body grew rapidly, the voice became deep, and hairs grew ad genitalia; at 6 years the development of the body was enormous; at 9 years of age the body length was $143 \mathrm{~cm}$., the weight 44 kilograms; the beard was abundant. The left testis proved, after orchidectomy, to be an alveclar carcinoma. Four months after the operation the beard disappeared, the hairs on the upper lip and genitalia persisted. The voice became again infantile, the penis less large and thick, the sexual impulses, emissions and erections ceased; also the character reverted to the infantile stage.

These tumors of the genitive glands suggest that the irritation of the latter causes an excessive and premature increase of the function of the interstitial tissue of Leydig, hastening the development of the secondary sexual characteristics.

Bulloch and Sequeira ${ }^{19}$ compiled ten cases, eight girls and two boys, in which necropsy revealed tumors of the adrenals. One case of precocity in boys was the case of Linser, ${ }^{20}$ in which a hypernephroma was found; the testes were of the size of a pigeon's egg and the prostate corresponded in size to that of a boy 15 years old. The other case, observed by Adams, ${ }^{21}$ was in a boy not yet 15 years old, who died one year later of metastases of hypernephroma. Later, Glynn ${ }^{22}$ brought the number up to seventeen cases in children; fourteen females and only three boys.

According to clinical and pathologic observations, we must ascribe to tumors of the adrenals merely a hastening influence on the development of the secondary sexual characteristics, causing also an excessive growth of the body, since other recognizable functions of the sexual glands, such as menstruation or ejaculation, are not mentioned in these reported cases. It seems that although the hyperfunctionary tumors of the cortex of the adrenals in the young give rise to greatly accelerated growth of the body and to premature development of secondary sexual characteristics, as a rule, it is so without any manifestation of a secretion of the generative cells. In such cases, with Tandler and Gross one might think of a premature function of the Zzrischensubstanz without premature development of the germinative cells.

18. Sacchi: Riv. sper. di freniat., 1895, 21.

19. Bulloch and Sequeira: Tr. Path. Soc., London, 1905, 56.

20. Linser: Beitr. z. Klin. Chir., 1903, 37, 282.

21. Adams, Ch.: Tr. Path. Soc., London, 1905.

22. Glynn: Quart. Jour. Med., 1912, 5, 157. 
In five cases, all boys, reported by Gutzeit, Cyrill Ogle ${ }^{28}$ (sarcoma), Oestreich-Slawyk, ${ }^{24}$ Frankl-Hochwart ${ }^{25}$ and Raymond Claude, ${ }^{26}$ postmortems revealed teratomas of the pineal gland; Horrax' ${ }^{27}$ case revealed at postmortem a struma of the pineal. It is not a mere coincidence, probably, that the pineal tumors were found only in male precocious children, whilst the adrenal hypernephromas are five times more frequent in the female than in the male.

The relation between genital hypertrophy and the pineal gland, according to Marburg, ${ }^{28}$ is perhaps to be interpreted as due to a premature decrease of the functionating glandular tissue, which otherwise under normal conditions undergoes degeneration, beginning with the seventh year of life. The trophic disturbance, that is, the premature development, or as Pelizzi ${ }^{4}$ terms it, the macrogenitosomia praecox, may be considered as a manifestation of the insufficiency ( $A u s f a l l$ ) of the epiphyseal gland. We have to presume that in childhood normally the pineal gland exerts an inhibitory influence on development, and that later the influence gradually diminishes and disappears, due to the partial involution of the gland. This interpretation of the premature development being due to hypopinealism finds its support in the results of experiments by Foa, ${ }^{29}$ who, after extirpation of the epiphyseal gland in young roosters, observed a premature and excessive development of the testes and some secondary sexual characteristics.

The reports of positive findings made by Horrax ${ }^{27}$ are in keeping with those of Foa. ${ }^{29}$ The pinealectomized male guinea-pigs showed a hastened development of the sexual organs, manifested before maturity by a relative increase in size and weight, both of the testes and seminal vesicles, over control pigs of the same litter. The pinealectomized females appear to show a tendency to breed earlier than controt animals.

On the other hand, extirpation of the generative glands in young animals has been followed by atrophy of the pineal gland (Biach and Hulles $^{30}$ ). The case of Marburg ${ }^{28}$ also supports the supposition of the epiphyseal gland exerting an influence on the premature sexual development. The examination of the brain of the 9-year-old idiot with well developed crines pubis revealed a markedly inhibited development of the pineal gland, with entirely fetal cell-islands and a marked gliaplaque in its interior.

23. Ogle, Cyrill: Tr. Path. Soc., London, 1899, 50, 4.

24. Oestreich-Slawyk: Virchows Arch. f. path. Anat., 1899, 157, 475.

25. Frank1-Hochwart: Deutsch. Ztschr. f. Nervenh., 1909, 37.

26. Raymond-Claude: Bull. de l'Acad. d. méd., Paris, 1910, 63, 265.

27. Horrax: Arch. Int. Med., 1916, 17, 607, 645.

28. Marburg: Ergebn. d. inn. Med. u. Kinderh., 1909, 4. Ibid., 1913, 10, 146.

29. Foa: Arch. Ital. de biol., 1912, 57, 233.

30. Biach and Hulles: Wien. klin. Wchnschr., 1912, No. 10, p. 373. 
Marked hydrocephalus was found post mortem in the $81 / 2$-year-old girl reported by Wetzler. As early as in the sixth year of life menstruation took place, and the external genitalia were well developed and covered with hairs; uterus and ovaries had the size of those of a 20 -year-old person. It is possible that this case belongs to primary hypergenitalism as well as a similar one of Pellizzi.4

Our positive knowledge of the etiology and pathologic anatomy is limited to those few cases. In a few observations premature sexual development has been ascribed to such early and excessive practices as masturbation and cohabitation due to seduction. Where such pathologic factors are absent, what the cause of the prematurity of the impulses for the somatic changes is remains a problem, as it is likewise not known why at a certain period of life under physiologic conditions certain organs should increase rapidly and perfect their function, the sexual glands particularly receiving impulses that cause a more rapid maturing. Though the nature of the primary stimuli that control these changes is not known, it is established that the endocrine glands in their interlocked and mutually affecting functions are of the greatest importance for the normal growth of the body and for sexual maturity, among them especially the genital glands, the adrenals, the pituitary body, the thyroid and the so-called "puberty-glands," the thymus and the pineal; their inextricable interaction in the main still defying analysis; the inner working of biologic laws, of the phylogenetic, hereditary and racial factors, of climate, etc., that regulate the onset of these processes remains obscure.

The following case of precocity was observed by me in the Cook County Hospital. The coincidence of imbecility renders the case more interesting and adds to the list of observations as exemplified by the reports of the authors before mentioned.

\section{CASE REPORT}

History.-K. W., 111/2 years old, son of Ruthenian immigrants. The father is middlesized, of sturdy build, living at present out of Chicago; mother small. There were two other children with irrelevant histories. The patient was born at full term, weighed, allegedly, 7 pounds. He grew first slowly, more rapidly at 5 years of age; he has always been mentally much below par and somewhat hard of hearing, according to his mother's statement. He learns poorly, has a very poor memory and is in the first grade of the public school where he has attended for three years. He has had measles, scarlatina, diphtheria and whooping cough. He often snores and sleeps with open mouth. He began to grow rapidly about one year prior to this report; no information can be obtained from the mother about the sexual development of her boy; neither does she remember when he began to walk and talk.

Present Status.-The patient is of slender build, of blond type; height 1.51 $\mathrm{m}$.; weight 85 pounds, with waist and coat off. The lower half of the body, measured from the lower edge of the symphysis to the heel, is $75 \mathrm{~cm}$. The musculature is flabby and poorly developed; head rachitic, tubera frontalia and 


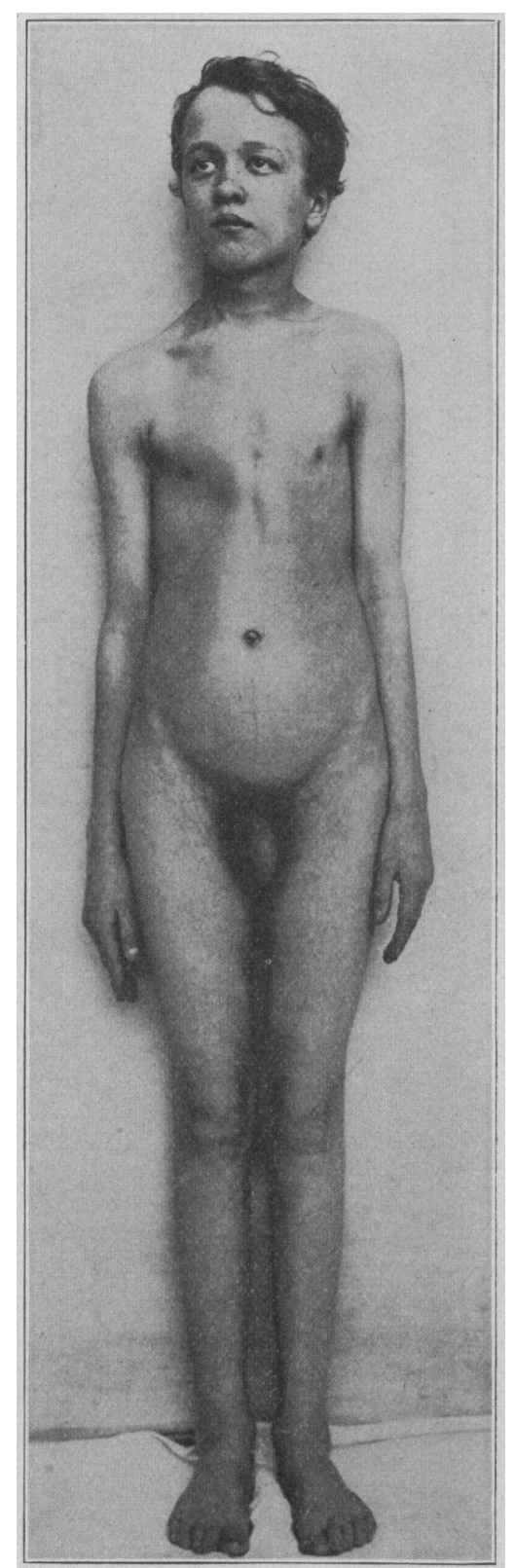

Author's case of sexual precocity. Boy aged 11/2 years. 
parietalia prominent; fronto-occipital circumference, $55 \mathrm{~cm}$; there are twentyeight perfect teeth; no trace of caries; chest poorly developed; chicken-breast deformity; circumference in nipple-line during middle respiratory position, $67.5 \mathrm{~cm}$. The lower part of the abdomen is somewhat pendant, the muscles of the abdominal wall flabby and poorly developed. There is a slight degree of genu valga and beginning pedes valgi.

Genitalia.-In comparison with the age of the boy his genital organs are striking in their degree of development; there are also some secondary sexual characteristics present. The penis is $10.6 \mathrm{~cm}$. long measured from the root at the symphysis to the end of the prepuce, and $9 \mathrm{~cm}$. in circumference in the nonerected state. The prepuce reaches about $1 \mathrm{~cm}$. beyond the glans. The testicles are of the size of those in the adult man, $3.5 \mathrm{~cm}$. to $4 \mathrm{~cm}$. long, the left larger than the right. There is an abundant growth of hair on the pubes, more than $5 \mathrm{~cm}$. long; the upper border line is of feminine type; there is a conspicuous brown pigmentation of the median line from the mons veneris to the umbilicus. The scrotum is covered with a few hairs, 0.5 to $1 \mathrm{~cm}$. long. In both axillae there are patches of skin of 1.5 to $2.5 \mathrm{~cm}$. diameters that are covered with a crop of blond hair about $1 \mathrm{~cm}$. long. The boy has vigorous erections of the penis, as was witnessed in the hospital. The prostate gland is of the size of that of an adult. Massage of the prostate and seminal vesicles, performed once, did not yield sperma. The larynx is very prominent, the voice strikingly deep.

The inner organs show no abnormal conditions; no tumor of the kidneys can be palpated, neither does roentgen-ray examination reveal any anomaly of these organs. The roentgenogram of the skull demonstrates a slightly enlarged sella turcica and a moderate increase in size of the skull. Roentgenograms of the hand show no deviation from the ossification that corresponds to the actual age of the boy. The ear drums are only slightly retracted, the hearing little affected.

Psychic Conditions and Habits.-The boy is very.irritable; "nervous"; cries when his mouth is inspected. He is of a stubborn, disobedient, troublesome disposition, and resentful toward other children, and has to be reprimanded for it in the hospital. At home he prefers to play with boys younger than himself and shuns boys of his size; there are evidences of sexual shame; he chews his nails habitually; these are much bitten off. There seems to be at present no particular propensity to the other sex. He cannot count to more than five; even then he must be helped. He cannot write his name unless a copy is placed before him; his handwriting is hardly readable; nor can he do sums; he says for instance, 2 and 2 are 3,2 and 2 are 6; 1 and 1 are 7 . $\mathrm{He}$ is not able to say his prayers without being helped by his mother; he does not know any verses or any song, although he has attended, as mentioned before, the public school for three years. In fact, he is too dull to answer simple questions that refer to his own person, and during the examination he gives many evidences of a very poor memory even as to occurrences and experiences that would seem important to a normal boy.

Etiologically, the case may be classified as (primary) hypergenitalism without anatomicopathologic changes. The clinical examination excludes a tumor of the adrenals and there is no ground for suspecting a tumor of the pineal gland, corresponding cerebral symptoms being entirely wanting. Further, the makrogenitosomia praecox due to hypopinealism occurs only through premature destruction of functionating pineal tissue, that is, before the seventh year of life, since at that time the involution normally commences. 
Against a hypophyseal affection (hyperpituitarism) militates the absence of such characteristic symptoms as were observed in the rare cases of acromegaly in adolescence and childhood. (Cases of Arnold, Claude, Schultze-Fischer, Hutinel, Pel and Salle, the two latter since birth. Quoted from Falta. ${ }^{31}$ ) The slight enlargement of the sella turcica hardly has any bearing in our case, considering the hydrocephalic increase in size of the skull of the boy.

4557 Broadway.

31. Falta, W.: The Ductless Glands (Translation from the German), p. 272. 